\title{
THE LEGISLATIVE REGULATION OF "SMART" CONTRACTS: THE PROBLEMS AND PROSPECTS OF DEVELOPMENT
}

\author{
Irina A. Mitrofanova \\ Volgograd Institute of Management - Branch of the Russian Presidential Academy of National Economy and \\ Public Administration, Volgograd, Russian Federation
}

Introduction: currently, the whole world is experiencing tremendous changes in connection with the transition to the information society. This work is devoted to the challenges faced by contract law. The aim of this work is to study the theoretical and practical problems of the legal regulation of "smart" contracts. Methods: the methodological framework for the study is the dialectical method of cognition, which assumes the comprehensiveness, objectivity and interconnectedness of the studied phenomena; the general scientific methods of cognition (analysis, synthesis, hypothesis, analogy, etc.); the comparative law and functional methods. As a result of the study, the main problems arising in the legislative regulation of "smart" contracts were grouped. The technical ones include: the problem of describing the conditions in the artificial language, obtaining the data from the real world by the system, the reliability of the input data, the system errors, the speed of transaction processing, the inability to maintain the complete confidentiality of the operations. The legal problems include: the complexity of the contract verification by a lawyer, the lack of control of transactions by the state and tax authorities, the possibility of illegal transactions, the complexity of proving the fact of the contract, the definition of the applicable law, remedies. The legislation of some foreign countries, which is also under development, is analyzed. The analysis of the draft law "On Digital Financial Assets" shows that the document does not satisfy the requests for the legal regulation of the digital economy. In the definition, there is no indication that a "smart" contract is written in the artificial language, the turnover of the crypto currency is significantly limited. It is concluded that a "smart" contract is now rational to use as part of a paper contract for simple transactions with the measurable conditions. The draft law "On Digital Financial Assets" needs the significant improvement to simplify the turnover of digital assets and the development of the institution of "smart" contracts.

Key words: "smart" contract, digital financial asset, blockchain, obligation, crypto currency.

Citation. Mitrofanova I.A. The Legislative Regulation of "Smart" Contracts: the Problems and Prospects of Development. Legal Concept, 2018, vol. 17, no. 4, pp. 22-29. DOI: https://doi.org/10.15688/lc.jvolsu.2018.4.3

\section{ЗАКОНОДАТЕЛЬНОЕ РЕГУЛИРОВАНИЕ «УМНЫХ» КОНТРАКТОВ: ПРОБЛЕМЫ И ПЕРСПЕКТИВЫ РАЗВИТИЯ}

\author{
Ирина Александровна Митрофанова \\ Волгоградский институт управления - филиал Российской академии народного хозяйства \\ и государственной службы при Президенте РФ, г. Волгоград, Российская Федерация
}

Введение: в настоящее время весь мир переживает колоссальные изменения в связи с переходом к информационному обществу. Данная работа посвящена вызовам, с которыми сталкивается договорное право. Целью настоящей работы является исследование теоретических и практических проблем правового регулирования смарт-контрактов. Методы: методологическую основу исследования составляют диалектический метод познания, предполагающий всесторонность, объективность и взаимосвязанность исследуемых явлений; общенаучные методы познания (анализ, синтез, гипотеза, аналогия и т. д.); сравнительно-правовой, функциональный методы. 
В результате исследования были сгруппированы основные проблемы, возникающие при законодательном регулировании смарт-контрактов. К техническим относятся: проблема описания условий на искусственном языке, получение системой данных из реального мира, достоверность вводимых данных, ошибки системы, скорость обработки транзакций, невозможность соблюдать полную конфиденциальность проводимых операций. К правовым проблемам относятся: сложность проверки контракта юристом, отсутствие контроля проводимых сделок со стороны государства и налоговых органов, возможность проведения противозаконных сделок, сложность доказывания факта совершения контракта, определение применимого права, судебная защита. Проанализировано законодательство некоторых зарубежных стран, которое также находится в стадии разработки. Анализ законопроекта «О цифровых финансовых активах» показал, что документ не удовлетворяет запросы на правовое регулирование цифровой экономики. В определении отсутствует указание на то, что смарт-контракт записывается на искусственном языке, оборот криптовалюты существенно ограничен. Сделан вывод о том, что смарт-контракт в настоящее время рационально использовать как часть бумажного договора для совершения простых сделок, с измеримыми условиями. Законопроект «О цифровых финансовых активах» нуждается в существенной доработке для упрощения оборота цифровых активов и развития института «умных» контрактов.

Ключевые слова: смарт-контракт, цифровой финансовый актив, блокчейн, обязательство, криптовалюта.

Цитирование. Митрофанова И. А. Законодательное регулирование «умных» контрактов: проблемы и перспективы развития // Legal Concept $=$ Правовая парадигма. -2018 . - Т. 17, № 3. - C. 22-29. - DOI: https: //doi.org/10.15688/lc.jvolsu.2018.4.3

\section{Введение}

В настоящее время социум, экономическая и правовая системы испытывают на себе огромное влияние информационных технологий. Те возможности, которые предоставляет нам сеть Интернет, не всегда поддаются адекватному правовому регулированию. Это абсолютно новая сфера правового «контроля», который пока что довольно трудно осуществлять.

Тем не менее правовая система должна своевременно и всесторонне реагировать на происходящие изменения.

Сейчас все большее внимание исследователей привлекают так называемые «умные» контракты (“smart" contract). Но так как они существуют в «другой» реальности, возникают вопросы их законодательного регулирования.

\section{Определение термина «смарт-контракт»}

В последние несколько лет в обиход прочно вошли такие понятия, как «биткоин», «блокчейн», «криптовалюта» и т. п. Именно технология blockchain (блокчейн) позволила создавать не только цифровую «валюту», но и смартконтракты.

Смарт-контракт - это самоисполняемый договор, записанный программным кодом на основе технологии blockchain [9, с. 41]. То есть это договор, который записывается на языке программирования (искусственном языке) и скрепляется электронной цифровой подписью каждой из сторон (или удостоверяется специальным ключом). Заключаются такие контракты в децентрализованной среде с использованием определенного протокола (например, площадка Ethereum), что позволяет обмениваться активами без посредников.

Нельзя сказать, что смарт-контракты прочно вошли в обыденную практику, но, тем не менее, многие крупные компании уже заключают договоры в таком формате [4]. Например, Альфа-банк и S7 проводили первую финансовую сделку с применением блокчейн в России. Использовались сразу два смартконтракта - для открытия и исполнения (закрытия) аккредитива. Учитывая все плюсы такого рода контрактов, можно с уверенностью говорить о том, что назрела необходимость законодательно регулировать этот вид правоотношений, ведь число подобных сделок будет возрастать.

Итак, первый вопрос, возникающий на законодательном уровне, - вопрос определения самого понятия смарт-контракта. В законопроекте «О цифровых финансовых активах», разработанном в нашей стране, такое определение дано в следующем виде: «Смарт-контракт - договор в электронной форме, испол- 
нение прав и обязательств по которому осуществляется путем совершения в автоматическом порядке цифровых транзакций в распределенном реестре цифровых транзакций в строго определенной им последовательности и при наступлении определенных им обстоятельств».

Заслуживают внимания два аспекта: насколько корректно подобное определение и нужно ли выносить его в отдельный законодательный акт?

Для ответа на первый вопрос были проанализированы определения, которые дают исследователи в различных областях знаний (не только юристы, но и технические специалисты). Основными признаками смарт-контракта единогласно признаются: запись на искусственном языке (язык программирования), самоисполнимость, существование в пределах платформы блокчейн и использование криптовалюты как основного средства расчетов. На наш взгляд, в определении, данном законодателем в проекте, упущено важное замечание о том, что сам договор составлен на языке программирования, и это кардинально отличает его от иных форм договора. Также в законопроекте существенно ограничивается оборот криптовалюты, что сделает (в случае принятия в неизменном виде) применение смарт-контрактов довольно затруднительным.

Но учитывая даже данное в законопроекте о ЦФА определение, возникает закономерный вопрос о рациональности выноса формы смарт-контракта в отдельный законодательный акт. В Гражданском кодексе РФ определены две формы договора: устная и письменная. Причем письменная форма подразумевает обмен «электронными документами, передаваемыми по каналам связи, позволяющими достоверно установить, что документ исходит от стороны по договору». А электронным документом признается «информация, подготовленная, отправленная, полученная или хранимая с помощью электронных, магнитных, оптических либо аналогичных средств, включая обмен информацией в электронной форме и электронную почту». Является ли программный код информацией? Безусловно. Блокчейн - технология, которая позволяет взаимодействовать контрагентам и создавать, обмениваться такой информацией. Поэтому, на наш взгляд, логично будет приравнять смарт-контракт к письменной форме договора и тем самым устранить препятствия к их заключению. Ведь психология и логика многих юристов (особенно это касается судебной системы) исходит из того, что если данный вид договора прямо не указан в законе, то есть опасность в дальнейшем признания этого договора недействительным.

Смарт-контракт интересен не только тем, что имеет необычную форму своего существования. Это совершенно особый способ исполнения обязательства. Если заключая обычный договор стороны подразумевают совершение ими определенных действий, то при создании смарт-контракта больше никаких действий от сторон не требуется. Все обязательства будут осуществляться в автоматическом режиме без участия человека. То есть смарт-контракт должен быть рассмотрен не как некий отдельный специфический вид обязательства, а как особый способ исполнения обязательств по договору.

\section{Проблемы применения и правового регулирования смарт-контрактов}

От определений перейдем к непосредственной регуляции. Смарт-контракты вызывают интерес у общества в первую очередь потому, что имеют ряд преимуществ перед традиционными контрактами: отсутствие посредников, автоматическое исполнение (не зависящее от желания контрагента, который может, например, задержать платеж или вовсе его не осуществить), жесткая регламентация и истолкование заданных условий, невозможность вмешаться извне в заданный код и т. п. Если рассматривать «идеальную» концепцию смарт-контракта, то его использование может существенно сократить не только издержки организации на заключение договора, проведение транзакций и т. п., но и количество судебных споров.

Однако не все так просто, и существует немало проблем для законодателя и тех, кто хотел бы использовать такого вида договор. Основные проблемы можно разделить на технические и правовые.

Первый и самый очевидный вопрос возникает в связи с тем, что смарт-контракт за- 
писан на искусственном языке. Язык программирования предполагает высшую степень определенности. Возможно ли с помощью него описать все, что может существовать в реальном мире? Например, категория «разумный срок» явно не может быть вписана в программный код, так как не имеет рамок и рассматривается с субъективной точки зрения, в зависимости от конкретных обстоятельств. Понятно, что программа таких выводов сделать не может. Получается, что качественный смарт-контракт может быть создан только при наличии вполне определенных и поддающихся вычислению условий.

Привязка к реальному миру также является слабой стороной смарт-контрактов. Ведь система должна получать из внешнего мира данные о наступлении определенных условий. Для выполнения этой функции предназначены так называемые программы-оракулы. Однако эксперты отмечают недостаточную развитость таких программ. Смарт-контракты существуют в своей среде, среде блокчейн-платформы. Соответственно, им всегда доступны данные, которые существуют также в пределах платформы. Например, факт совершения транзакции криптовалюты. Получение данных извне все еще остается не такой простой задачей. Причем эти данные не только должны оперативно поступать в систему, но и быть достоверными. Кто и как должен проверять достоверность этих данных?

По поводу оперативности в последнее время тоже наблюдаются сложности [1]. По всей видимости, блокчейн-платформы не приспособлены к обработке слишком большого объема данных. В сети год назад уже велось активное обсуждение того, что из-за блокчейнигры CryptoKitties транзакции на платформе Etherium зависали на несколько дней. А это, между прочим, та самая платформа, которая провозглашает себя наиболее подходящей для создания и функционирования смарт-контрактов. Система просто не справилась с огромным объемом входящих и исходящих данных.

Еще одна техническая проблема может быть связана с ошибками как внутри системы, так и при вводе данных. Все мы знаем, что любая техника не может быть на $100 \%$ надежной и безотказной, поэтому и в систему, обеспечивающую работу контракта, мо- жет закрасться ошибка. Кто будет отвечать за такую ошибку и ее последствия - неясно.

Помимо этого, ошибки могут возникать при вводе данных. Так как смарт-контракт формируется в виде кода на определенной блокчейн-платформе, соответственно, его условия формирует одна из сторон либо привлеченный специалист. Получается, что и на этой стадии могут быть совершены ошибки. А как мы знаем, изменению смарт-контракт не подлежит. В этом можно найти еще один минус недостаточная гибкость по сравнению с традиционным договором.

Все вышеперечисленные проблемы наталкивают на мысль о том, нужна ли столь высокая степень автоматизированности контракта. На практике сложились три типа смарт-контрактов: полностью автоматизированные, с копией на бумажном носителе и преимущественно на бумажном носителе, но с автоматизацией некоторых процессов [10].

Полностью автоматизированные смартконтракты не имеют копии на бумажном носителе и полностью выражены в программном коде. На наш взгляд, такие контракты имеют право на существование, но лишь для решения простых задач. То есть если условия договора довольно просты, поддаются измерению и имеют больше «техническое» назначение (например, совершение платежа с наступлением определенной даты), то применение вполне рационально.

Смарт-контракт с копией на бумажном носителе имеет более сложные условия, что не позволяет обойтись только программным кодом. На наш взгляд, в таких случаях использование смарт-контракта не представляется обоснованным и свидетельствует об опасениях сторон по поводу точности не только исполнения, но и толкования условий, которые должны быть записаны в программный код. Смарт-контракты призваны упростить экономический оборот, а в данном случае получается дублирование и выполнение ненужной работы.

В настоящее время более распространен третий вид контрактов - когда есть основной договор на бумажном носителе, а действия «технического» характера «поручены» программе. Видимо, на сегодняшний день такая форма является компромиссной 
и позволяет обойти острые углы и восполнить пробелы в коде. Например, на бумаге может быть прописан порядок разрешения споров [2]. Ведь такое условие прописать в виде кода просто невозможно. Одним из вариантов может быть заключение рамочного соглашения, в котором предусмотрено использование в дальнейшем цифровых контрактов.

Теперь обратимся к проблемам правового свойства.

Очень тесно связан с проблемой применения языка программирования вопрос проверки контракта юристом. Любой договор предполагает установление (прекращение, изменение) прав и обязанностей у каждой из сторон. Как указывалось выше, «умный» контракт формируется одной из сторон. Вторая сторона, чтобы принять условия, должна, как минимум, понимать, о чем идет речь и какие конкретно условия прописаны в договоре. Без знания языка программирования сделать это невозможно, как и представить то, что каждый юрист такой язык знает. Получается, в любой компании, которая заинтересована в использовании смарт-контрактов, должен появиться специалист, обладающий знаниями не только юриста, но и программиста.

В этом же поле находится проблема контроля со стороны государства, в том числе налоговых органов. Ни для кого не секрет, что существует особая зона Всемирной сети так называемый Darknet, где возможно провести противоправные сделки, такие как покупка оружия, наркотических веществ, оплата противозаконных услуг и т. п. Не удивительно, что платформа блокчейн, которая гарантирует анонимность участников (а проследить можно лишь транзакции), подходит для осуществления противозаконных действий. И государственные органы не могут отследить такие действия.

Даже если содержание сделки не является противозаконным, то каким образом ее должны учитывать налоговые органы? Сведения о такой сделке могут лишь добровольно подать контрагенты. В мире существует не одна платформа, где можно совершить подобную сделку, и, учитывая децентрализованный характер, не существует «суперполь- зователя», который бы предоставлял государству сведения обо всех заключающихся контрактах. В этом есть опасность и того, что сторонам может предстоять доказывание в суде самого факта заключения контракта (если он не продублирован на бумажном носителе).

Платформы блокчейн являются децентрализованными [6] и, в большинстве своем, открытыми. Соответственно, может появиться опасность утечки данных (в том числе учитывая участившиеся атаки на блокчейн-платформы). Многим крупным компаниям конфиденциальность данных может просто не позволить пользоваться «умными» контрактами и «открывать» системе свои данные. Каждый может проследить цепочку сделанных транзакций, сколько передано криптовалюты и т. п.

В правовом поле находится и проблема определения применимого права, если контрагенты принадлежат к различным государствам. С точки зрения международного частного права и теории коллизионного регулирования такая проблема является основной в принципе, но выработанные правила трудно поддаются применению к новой цифровой реальности. Контракт заключен не просто в цифровом виде, он написан на искусственном языке, существует в искусственно созданной реальности. Более того, исполнение контракта также происходит без участия контрагентов, автоматически. То есть коллизионные привязки типа «место исполнения договора», «место заключения контракта», «закон, с которым правоотношение наиболее тесно связано» просто не имеют смысла. А если возникнет спор между сторонами (в случае отсутствия копии или рамочного соглашения на бумажном носителе), то придется урегулировать вопросы, связанные с местом рассмотрения спора, затем в суде доказывать, что договор действительно был заключен и исполнен, «переводить» условия договора на естественный язык и т. П. И все это может быть связано еще и с определением применимого права.

Логично было бы задать изначально как условие применимое право. Но каким образом сформулировать это условие и что программа будет с ним делать - неясно. 


\section{Российское}

\section{и зарубежное законодательство \\ в сфере цифровой экономики}

Законодателю придется сделать все, чтобы попытаться контролировать «умные» контракты. Такая задача стоит не только перед нашей правовой системой. Технология блокчейн распространена во всем мире и еще ни одна страна не нашла оптимального, универсального решения этой проблемы. Ведь перед тем, как приступать к регуляции смартконтрактов, нужно законодательно определить статус криптовалюты, возможность ее оборота, контролирующие органы и т. п.

В законопроекте «О цифровых финансовых активах» законодатель решил пойти по пути жесткого регулирования, предельно ограничить оборот криптовалюты [5], что вызвало множество негативных отзывов.

Из содержания законопроекта можно сделать два основных вывода: государство не знает, как регулировать оборот криптовалюты, и хочет законопроектом заставить всех пользователей пройти идентификацию, то есть максимально понимать, кто, чем и как занимается.

Первый вывод следует из того, что криптовалюта признается имуществом в электронной форме (цифровым финансовым активом) и не признается законным средством платежа на территории России [7]. Логика законодателя проста - мы не знаем, что с этим делать, поэтому признавать криптовалюту и каким-либо образом ее легализовывать не будем.

Второй вывод основывается на том, что практически в каждом абзаце законопроекта говорится о регистрации, идентификации пользователей и владельцев криптовалют, создании юридических лиц, которые будут следить и вести учет операциям, и т. п. Например, говорится о неком валидаторе, который должен быть участником сообщества, внутри которого происходят транзакции, и вести реестр таких транзакций, подтверждать их действительность. Или если пользователь захочет обменять криптовалюту на другой финансовый актив или, предположим, рубли, то сделать это можно будет только у оператора обмена, но прежде нужно будет завес- ти цифровой кошелек и пройти процедуру идентификации.

Конечно, если оставить законопроект в таком виде, то смарт-контракты на территории Российской Федерации будут иметь смысл только без использования криптовалюты, соответственно, сфера их применения будет существенно ограничена, если не сказать практически уничтожена. Пока что данный законопроект и та свобода, которую предоставил блокчейн пользователям, явно несовместимы, и вряд ли получится безболезненно внедрить подобное регулирование. Некоторые эксперты высказываются о том, что соблюдение такого закона будет просто невозможным [11].

С другой стороны, полная децентрализация каких бы то ни было экономических процессов внутри любого государства не является правильной с точки зрения теории государства в принципе. Касательно рассматриваемой нами темы данный законопроект если и улучшил положение смарт-контрактов, то совсем незначительно. Да, появилось определение, однако остается непонятным, отдельная ли это дефиниция, принципиально отличная от обычного договора? Применимы ли к «умным» контрактам традиционные положения об обязательствах? Получат ли смартконтракты судебную защиту? Если получат, то каким образом ее осуществить, учитывая бытие контракта в цифровой реальности?

Справедливости ради можно сказать о том, что многие государства также находятся в неком тупике и пока не предпринимают активных действий для правового регулирования смарт-контрактов и криптовалюты.

Криптовалюта может рассматриваться как имущество (США), активы (Швейцария, Сингапур), виртуальный товар (Китай) или вообще не признаваться финансовым продуктом (Великобритания). В Японии криптовалюта признана законным средством платежа, что, безусловно, явилось стимулом для заключения смарт-контрактов.

Настоящим новатором в сфере правового регулирования цифровой экономики стала Мальта. В конце июня 2018 г. Мальтийский парламент одобрил три закона о регулировании сферы криптовалют и блокчейна. Здесь будет создан специальный орган - Управление по цифровым инновациям Мальты, зада- 
ча которого - регулировании криптосферы (поддержка и развитие проектов на основе блокчейн, внедрение технологических инноваций, регуляция сервисов). Это стало толчком для привлечения инвестиций в страну, уже известно, что сюда переезжают офисы крупных бирж (Binance и OKEx) [8].

Проблемам применения технологии блокчейн уделил внимания и Европарламент. Однако никаких мер предпринято не было и в ближайшем будущем не планируется, чтобы не тормозить развитие технологии [3, с. 81].

\section{Заключение}

Технологии не стоят на месте, и правовая действительность должна меняться в том же ритме. Пока можно констатировать одно «умные» контракты могут широко применяться в качестве сделок, имеющих простые, измеримые условия. Исчезнут транзакционные издержки, кредитор будет уверен в исполнении договора. С другой стороны, законодатель пока что не может вмешиваться в сферу цифровых контрактов, не ограничивая свободу этой деятельности, которая и является высшей ценностью технологии блокчейн. Контроль должен быть сопряжен с признанием и легализацией новой действительности, так как уже очевидно - цифровая экономика реальна. Это абсолютно новый вызов и государству, и правовой системе. Вполне возможно, что в обозримом будущем юристам придется, помимо знаний законодательства, получать базовое образование программиста, чтобы органично вписаться в новую правовую действительность. На сегодняшний день, на наш взгляд, смарт-контракты могут быть органичным дополнением традиционных договоров, упрощать оборот посредством автоматизации некоторых процессов. Это обусловлено не только ментальной неготовностью законодателя, но и многими проблемами технологии, которая пока не может в полной мере отражать действительность.

\section{СПИСОК ЛИТЕРАТУРЫ}

1. Букатин, В. Тупые «умные контракты» / В. Букатин // Эксперт online. - Электрон. дан. -
Режим доступа: http://expert.ru/siberia/2018/01/ tupyie-umnyie-kontraktyi (дата обращения: 01.07.2018). - Загл. с экрана.

2. Вашкевич, А. Пять выводов о смарт-контрактах / А. Вашкевич // Zakon.ru. - Электрон. дан. 27.12.2017. - Режим доступа: https://zakon.ru/blog/ 2017/12/27/pyat_vyvodov_o_smart-kontraktah (дата обращения: 15.06.2018). - Загл. с экрана.

3. Вашкевич, А. Смарт-контракты: что, зачем и как / А. Вашкевич. - М. : Симплоер, 2018. - 89 с.

4. ВЭБ заключил первый смарт-контракт на блокчейне Etherium // Forklog. - Электрон. журн. Режим доступа: https://forklog.com/veb-zaklyuchilpervyj-smart-kontrakt-na-blokchejne-ethereum (дата обращения: 01.07.2018). - Загл. с экрана.

5. Документ от 25.01.2018. Проект федерального закона «О цифровых финансовых активах» // Минфин России : офиц. сайт. Документы. - Электрон. дан. - Режим доступа: https://www.minfin.ru/ru/ document $/$ ?group_type $=\& q_{-} 4=$ =ифровых + финансовых\&DOCUMENT_NUMER_4=\&M_DATE from $4=\& M$ DATE to $4=\& \bar{P}$ DATE from $4=\& P$ DA TE_to_4=\&t_4=1138707742\&order_4 $=$ P_DATE\&dir $4=\overline{\mathrm{DESC}}$. - Загл. с экрана.

6. Елкина, В. 4 примера использования Etherium в бизнесе / В. Елкина // Rubase. - Электрон. дан. - Режим доступа: https://rb.ru/story/ ethereum-in-business (дата обращения: 25.05.2018). Загл. с экрана.

7. Законопроект о цифровых финансовых активах : Какое регулирование для криптосферы в РФ предлагают депутаты // Дайджест DTI Algorithmic. Электрон. дан. - Режим доступа: https://blog.dti.team/ zakonoproiekt-o-cifrovih-finansovih-aktivah (дата обращения: 06.07.2018). - Загл. с экрана.

8. Муратова, М. Мальта приняла законы о блокчейне и ICO / М. Муратова // Журнал Insider.pro. - Электрон. дан. - Режим доступа: https: //ru.insider.pro/topnews/2018-06-27/malta-prinyalazakony-o-blokchejne-i-ico (дата обращения: 28.06.2018). - Загл. с экрана.

9. Савельев А. И. Договорное право 2.0: «умные контракты» как начало конца классического договорного права // Вестник гражданского права. 2016. - № 3. - С. 32-60.

10. Что такое смарт-контракты? // Forklog. Электрон. журн. - 19.10.2017. - Режим доступа: https://forklog.com/chto-takoe-smart-kontrakt (дата обращения: 15.06.2018). - Загл. с экрана.

11. Otter, Т. Обзор законопроекта «О цифровых финансовых активах»: что ждет российское криптосообщество? / T. Otter // Forklog. - Электрон. журн. - 26.03.2018. - Режим доступа: https://forklog.com/ obzor-zakonoproekta-o-tsifrovyh-finansovyh-aktivahchto-zhdet-rossijskoe-kriptosoobshhetvo/ (дата обращения: 15.06.2018). - Загл. с экрана. 


\section{REFERENCES}

1. Bukatin V. Tupye «umnye kontrakty» [Stupid "Smart Contracts"]. Expert Online. URL: http:// expert.ru/siberia/2018/01/tupyie-umnyie-kontraktyi (accessed 1 July 2018).

2. Vashkevich A. Pyat vyvodov o smartkontraktakh [Five Conclusions about Smart Contracts]. Zakon.ru., 2017. URL: https://zakon.ru/blog/2017/12/ 27/pyat_vyvodov_o_smart-kontraktah (accessed 15 June 2018).

3. Vashkevich A. Smart-kontrakty: chto, zachem i kak [Smart-Contracts: What, What for and How]. Moscow, Simplawyer Publ., 2018. 89 p.

4. VEB zaklyuchil pervyy smart-kontrakt na blokcheyne Etherium [VEB Concluded the First Smart Contract on the Blockchain Ethereum]. Forklog. URL: https://forklog.com/veb-zaklyuchil-pervyj-smartkontrakt-na-blokchejne-ethereum (accessed 1 July 2018).

5. Dokument ot 25.01.2018. Proekt federalnogo zakona «O tsifrovykh finansovykh aktivakh» [Draft Law 'About Digital Financial Assets' of 25 January 2018]. Official Website of the Ministry of Finance of the Russian Federation. URL: https://www.minfin.ru/ $\mathrm{ru} /$ document/?group_type $=\& \mathrm{q} 4=$ =цифровых + финансовых\&DOCUMENT_NUMER_4=\&M DATE from $4=\& M$ DATE to $\overline{4}=\& \mathrm{P}$ DATE from $\overline{4}$ 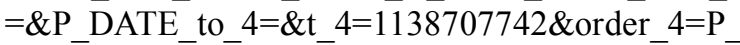 DATE\&dir $4=$ DESC.

6. Elkina V. 4 primera ispolzovaniya Etherium v biznese [4 Examples of Using Ethereum in Business].
Rubase. URL: https://rb.ru/story/ethereum-inbusiness (accessed 25 May 2018).

7. Zakonoproekt o tsifrovykh finansovykh aktivakh: Kakoe regulirovanie dlya kriptosfery v RF predlagayut deputaty [Draft Law 'About Digital Financial Assets': What Regulation Do Deputies Propose for Cryptosphere in the Russian Federation?]. Digest DTI Algorithmic. URL: https://blog.dti.team/ zakonoproiekt-o-cifrovih-finansovih-aktivah (accessed 6 July 2018).

8. Muratova M. Malta prinyala zakony o blokcheyne i ICO [Malta Adopts the Law about Blockchain and ICO]. Journal Insider.pro. URL: https:/ /ru.insider.pro/topnews/2018-06-27/malta-prinyalazakony-o-blokchejne-i-ico (accessed 28 June 2018).

9. Savelyev A.I. Dogovornoe pravo 2.0: «umnye kontrakty» kak nachalo kontsa klassicheskogo dogovornogo prava [Contract Law 2.0: Smart Contracts as the Beginning of the End of Classical Contract Law]. Vestnik grazhdanskogo prava, 2016, no. 3, pp. 32-60.

10. Chto takoe smart kontrakt? [What is Smart Contract?]. Forklog. URL: https://forklog.com/chtotakoe-smart-kontrakt (accessed 15 June 2018).

11. Otter T. Obzor zakonoproekta «O tsifrovykh finansovykh aktivakh»: chto zhdet rossiyskoe kriptosoobshchectvo? [Overview of the Draft Law "About Digital Financial Assets": What Is Waiting Russian Cryptocommunity?]. Forklog. URL: https:// forklog.com/obzor-zakonoproekta-o-tsifrovyhfinansovyh-aktivah-chto-zhdet-rossijskoekriptosoobshhetvo/ (accessed 15 June 2018).

\section{Information about the Author}

Irina A. Mitrofanova, Postgraduate Student, Department of Civil Law Disciplines, Volgograd Institute of Management - Branch of the Russian Presidential Academy of National Economy and Public Administration, Gagarina St., 8, 400131 Volgograd, Russian Federation, advance100@inbox.ru, https://orcid.org/0000-0001-9472-4381

\section{Информация об авторе}

Ирина Александровна Митрофанова, аспирант кафедры гражданско-правовых дисциплин, Волгоградский институт управления - филиал Российской академии народного хозяйства и государственной службы при Президенте РФ, ул. Гагарина, 8, 400131 г. Волгоград, Российская Федерация, advance100@inbox.ru, https://orcid.org/0000-0001-9472-4381 